\title{
Genetic Targeting in Cerebellar Purkinje Cells: an Update
}

\author{
Anna Slugocka $^{1,2}$ - Jan Wiaderkiewicz ${ }^{3}$ Jaroslaw J. Barski ${ }^{1,2}$
}

Published online: 11 March 2016

(C) The Author(s) 2016. This article is published with open access at Springerlink.com

\begin{abstract}
Since the last review paper published in Cerebellum in 2002 [1], there has been a substantial increase in the number of experiments utilizing transgenic manipulations in murine cerebellar Purkinje cells. Most of these approaches were made possible with the use of the Cre/loxP methodology and pcp2/L7 based Cre recombinase expressing transgenic mouse strains. This review aims to summarize all studies which used Purkinje cell specific transgenesis since the first use of mouse strain with Purkinje cell specific Cre expression in 2002.
\end{abstract}

Keywords Gene targeting $\cdot$ Cerebellum $\cdot$ Purkinje cells · Mouse

\section{Introduction}

After many years of research, there is still no consensus on the function of the cerebellum. It is accepted today that the cerebellum has a much more broad role than simply that of motor coordination. Purkinje cells (PCs), which are the sole efferent

Jaroslaw J. Barski

jbarski@sum.edu.pl

1 Center for Experimental Medicine, School of Medicine in Katowice, Medical University of Silesia, Katowice, Poland

2 Department of Physiology, School of Medicine in Katowice, Medical University of Silesia, Katowice, Poland

3 Department of Pharmacology \& Physiology, The George Washington University, 2300 Eye St., NW, Washington, DC 20037, USA output of the cerebellum, are one of few neuronal populations that express highly specific genes.

This review will focus mainly on the Cre/loxP recombination system, which is a unique tool for Purkinje-cell specific trangenesis that employs the Purkinje cell specific gene coding L7 or pcp2 (Purkinje cells specific protein-2). This protein was described for the first time in 1988 by two independent groups and this was the starting point of Purkinje cell specific transgenesis $[2,3]$. In the following text, we will use official nomenclature of pcp2 according to the Mouse Genome Informatics database at www.jax. org.

The gene coding pcp2 is located on the mouse chromosome $8[4,5]$. Initial studies of the gene structure described four exons $[6,7]$. These exons cover approximately $6 \%$ of the gene locus spanning $8 \mathrm{~kb}$. Transcription results in mRNA encoding a protein of approximately $16 \mathrm{kDa}$ [2]. Translation start is at the ATG codon in exon 2 and the reading frame includes the entire exon 3 and part of exon 4. Mature pcp2 proteins incorporate a $\mathrm{G}$ protein-regulatory motif (GPR), the GoLoco motif [8,9]. Experiments on the biochemical properties of pcp2 revealed its modulatory role in GDP release from $\mathrm{G}_{\mathrm{i}}$ and $\mathrm{G}_{\mathrm{o}}$, and the physical interaction with $\mathrm{G}$ subunits $[8$, 10]. Later experiments confirmed the existence of three further exons present when the gene structure is alternatively spliced $[9,10]$. Alternatively spliced pcp2 variants give rise to three proteins of different molecular weight with different biochemical properties and possible differences in function $[8$, 11, 12] (Fig. 1).

Importantly, pcp2 is characterized by its very specific expression exclusively in PCs and retinal bipolar neurons [13, 14]. Expression of pcp2 starts within the first postnatal week and can be easily detected in Purkinje cells with Northern blotting [2, 3], in situ hybridization [2, 3, 10], Western blotting $[13,14]$, and immunohistochemistry $[13,14]$. 
Fig. 1 To date identified splice variants of the pcp2 gene

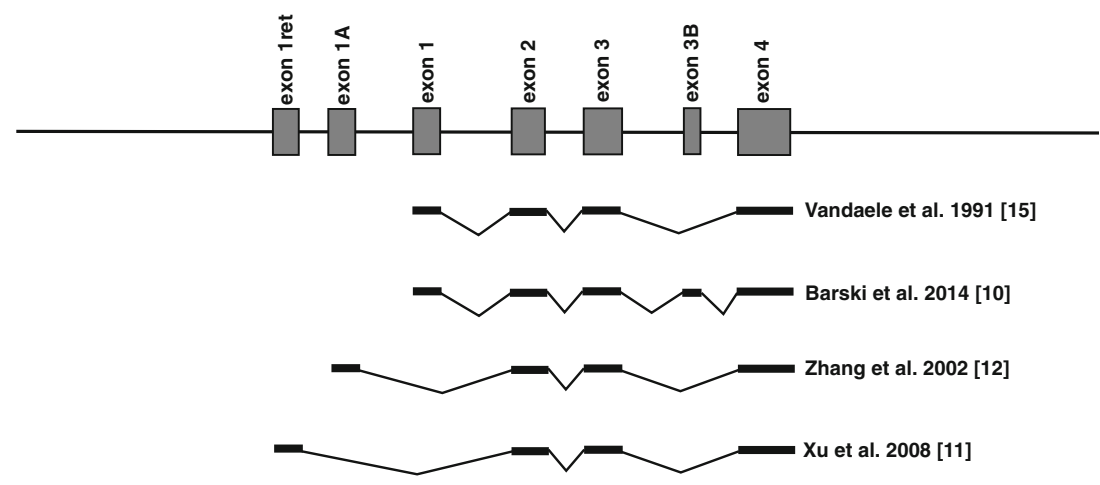

able to observe the chromogen or the fluorescence in the cells where recombination occurs (Fig. 3). Another recombination system accessible for gene targeting is based on the Flp recombinase [16]. This system can be combined with the $\mathrm{Cre} /$ loxP system to achieve recombination restricted to a subpopulation of cells. Both systems can be additionally modified by use of specifically designed inducible promoters. For more details see [1]

A big step forward in targeting of PCs was the generation of the L7 $\triangle$ AUG minigene by the John Oberdick group [17]. This construct was designed for easy insertion of DNA or cDNA sequences to express them specifically in Purkinje cells (Fig. 4). Because all transcription starts were removed from the pcp 2 coding sequences, it became possible to express the protein of choice only with the use of a co-inserted ATG, using only regulatory capacities of the construct. Accessibility of this very convenient tool enabled us to generate a transgenic mouse strain with Purkinje cell specific expression of Cre recombinase in 2000 [18]. In 2004 and 2005, the generation of another two transgenic strains were reported, which expressed Cre recombinase using regulatory elements of the pcp2 gene. The first of them was generated by means of an artificial BAC chromosome [19], and the other one using the knock-in approach with the help of homologous recombination [20]. The primary strain published in 2000 [18] is accessible at The Jackson Laboratory under the strain name: B6.129- $\mathrm{Tg}(\mathrm{Pcp} 2-\mathrm{cre}) 2 \mathrm{Mpin} / \mathrm{J}$. The BAC-based strain can be provided also by JAX under the name $\mathrm{B} 6 . \mathrm{Cg}-\mathrm{Tg}(\mathrm{Pcp} 2-$ cre) $3555 \mathrm{Jdhu} / \mathrm{J}$. The third one, the knock-in strain seems to be available only directly from the lab of origin. The first

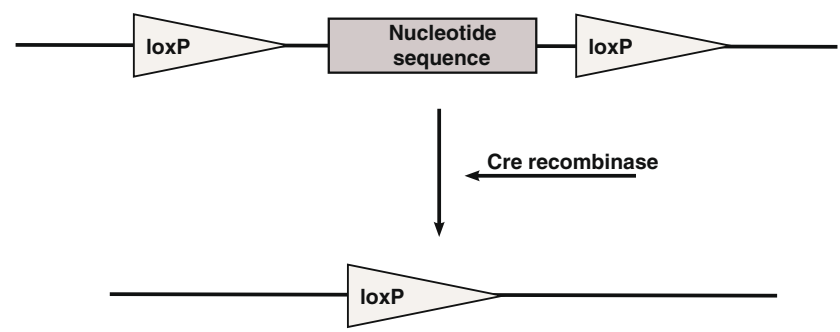

Fig. 2 Diagram showing the principle of Cre/loxP genomic sequence excision 


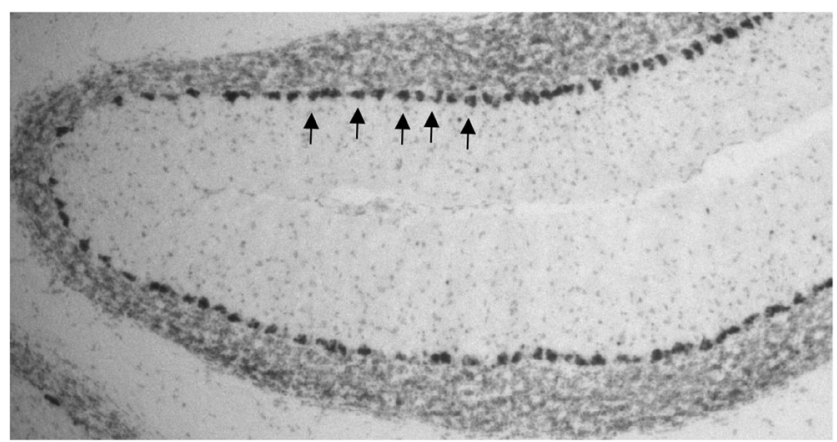

Fig. 3 Expression of $\beta$-galactosidase in Purkinje cells (black arrows) after crossing of B6.129- $\mathrm{Tg}(\mathrm{Pcp} 2$-cre $) 2 \mathrm{Mpin} / \mathrm{J}$ with the reporter strain-B6.129S4-Gt(ROSA)26Sortm 1Sor/J

created strain [18] became the most popular and since its establishment was applied over 60 times for genetic manipulations in murine cerebellum.

The use of pcp2Cre based genetic manipulations started in 2003. For the first time the pcp2Cre strain [18] was used by the M. Meyer's group for Purkinje cells specific knockout of calbindin D-28 k [21, 22]. The strain was created for this particular experiment to confirm the role of calbindin D-28 k in physiology of these neurons. Lack of calbindin D-28 k resulted in a very specific phenotype with clear signs of ataxia, however without signs of LTD disturbances. Detailed analysis of mutants revealed alteration in the early synaptic calcium transients (ESCT) without affecting the delayed synaptic calcium transients (DSCT). It is broadly accepted the DSCT are responsible for LTD, which seems to be independent from the calbindin D$28 \mathrm{k}$ expression. Presence of LTD was additionally confirmed by means of behavioral tests verifying motor-learning.

In the following text, we will briefly review all applications of all three pcp2Cre strains (Table 1).

Experimental approaches and studies summarized in Table 1 show clearly, how useful is the possibility to specifically manipulate gene expression in the cerebellar PCs. Published data allow for the manipulation of PCs function in many aspects and extend our knowledge on cerebellar physiology. Most of the experiments are typical conditional knockouts where expression of a selected gene is switched off according to the spatial and temporal expression of the pcp 2 gene. Some of the cited studies attempted to express conditionally selected

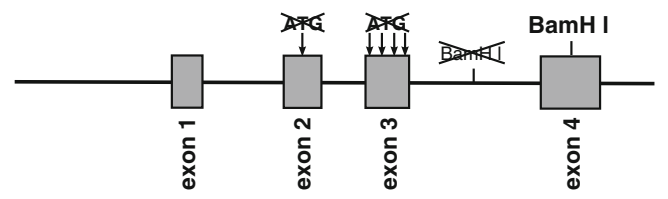

Fig. 4 Diagram of the L7 $\Delta$ AUG minigene. Note all mutated ATG and BamHI site. For easy insertion of nucleotide sequences there is the BamHI site in exon 4 genes using a similar approach as in the case of reporter mouse (Tab.1/5,6,15,18,22,30,43-45,56,60-63). In these experiments, $5^{\prime}$ to the coding sequence of nucleotides a floxed STOP cassette was placed. This kind of approach was also applied in the new field of conditional manipulation of neuron activity and namely in optogenetics (Tab.1/18, 44, 45, 56, 61, $63)$. This sophisticated method uses light to control activity of neurons or an individual neuron, which are sensitive light. The light sensitivity results from transgenic manipulations targeting expression of light-sensitive proteins to neurons. Optogenetics enables researchers to influence the activity of neurons in living animals, allowing for the precise recording of effects in real time.

Another group of experiments aimed to express heterological genes in PCs through the application of regulatory elements of pcp2 (Table 2).

Among these experiments, we can find four, which have important methodological input in the field of cerebellum research (Tab.2/1,2,4,6). Two of them resulted in stable expression of fluorescent proteins in PCs - GFP, Cerulean and Cherry (Tab.2/1,6). Another two experiments enabled researchers to specifically express a tetracyclin transactivator in these neurons (Tab.2/2,5).

In the following, we will discuss shortly results of selected papers, which are the most interesting from the authors point of view.

Shortly, after M. Meyer's group report [18] another work concerning motor learning using conditional knockout was published by Feil et al. in 2003. Investigators created a mouse without cGMP-dependent kinase I in PCs to study its role in LTD and cerebellar learning. Researchers emphasized, that cell specific ablation not only gave opportunity to overcome unwanted effect of conventional gene targeting which affects whole organism but also was privileged in that study because pharmaceutical tools had limitations. Firstly, there were no acknowledged specific cGKI inhibitor and secondly there was concern about the exaggeration of the importance of some pathways that might be less important, or even not used under physiological conditions. Tests revealed strongly reduced LTD and impaired adaptation of the vestibulo-ocular reflex in mutants. Results also showed a specific, indispensable role of cGPKI signaling in cerebellar LTD and motor learning. CGKI seems also necessary for motor coordination. Study strongly supports the conception that cerebellar LTD is involved in a specific form of motor learning but not in motor performance in general [23].

A group of publications investigating developmental relationships and refinement of neuronal connections have been initiated by Lorenzetto et al. In 2009, researchers employed a conditional overexpression of muscle chloride channel-YFP fusion protein by means of Cre-loxP system exclusively in PCs and provide a new tool to verify the role electrical activity for elimination of supernumerary climbing fiber inputs. Their 


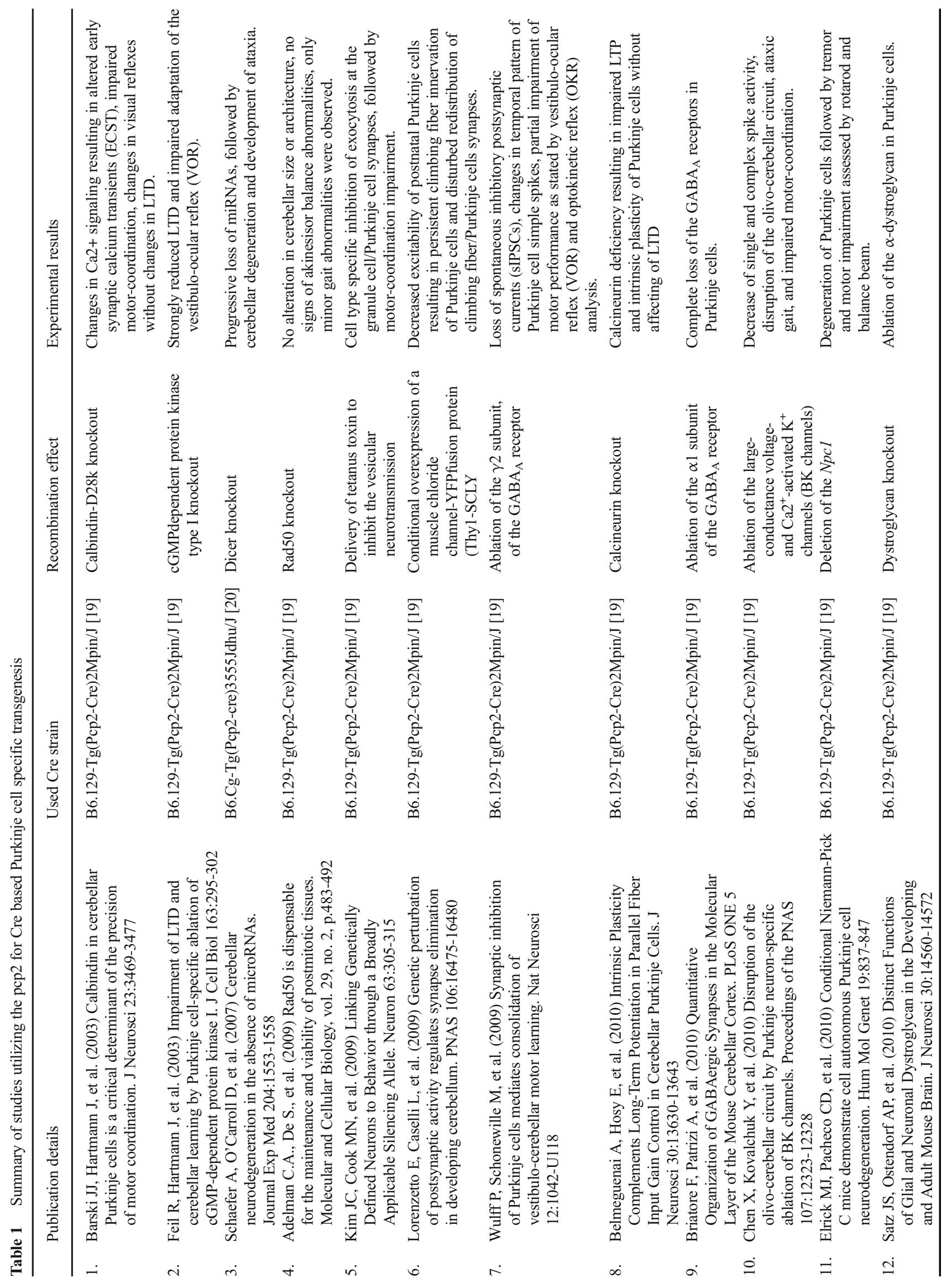




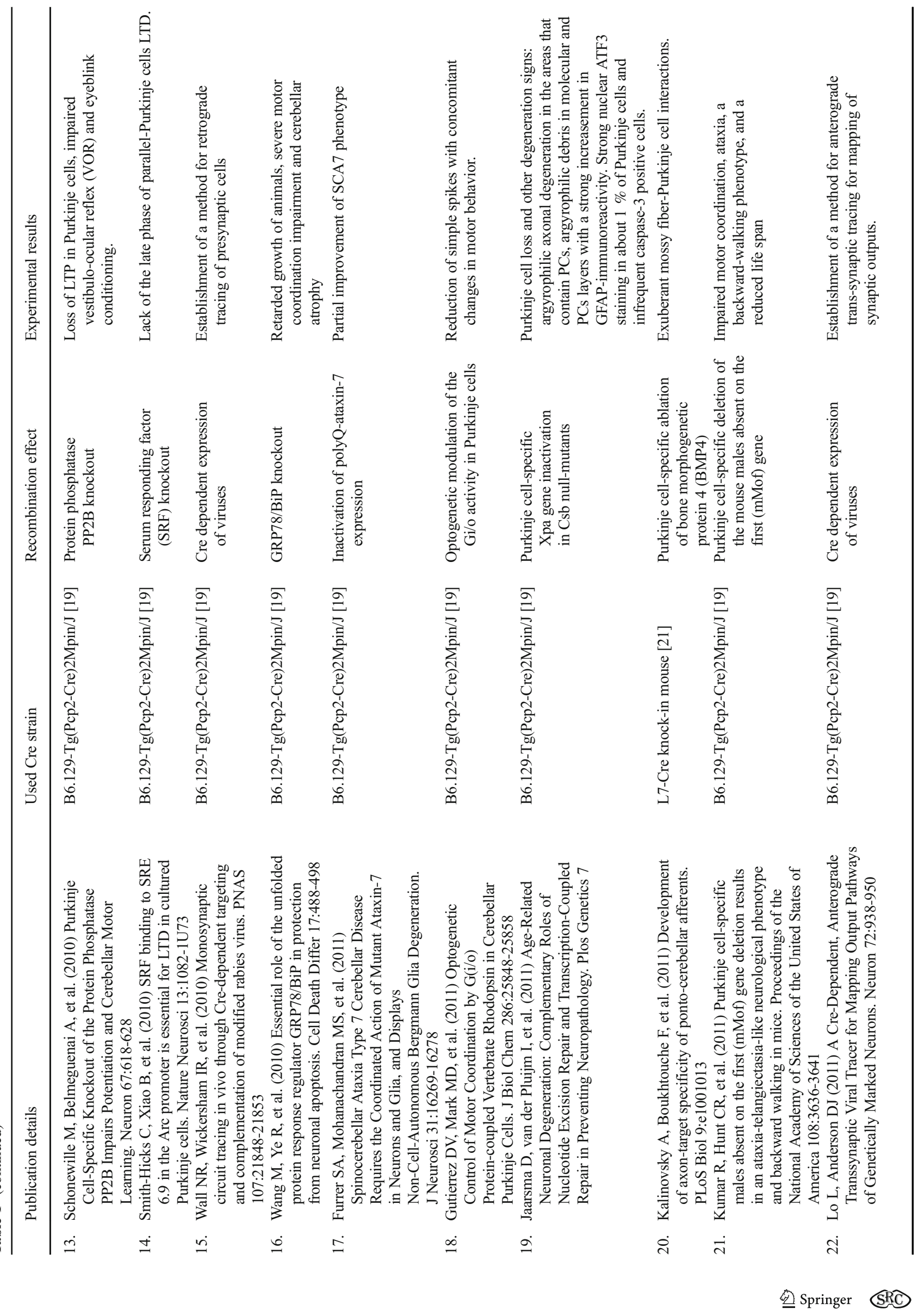




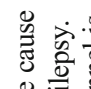

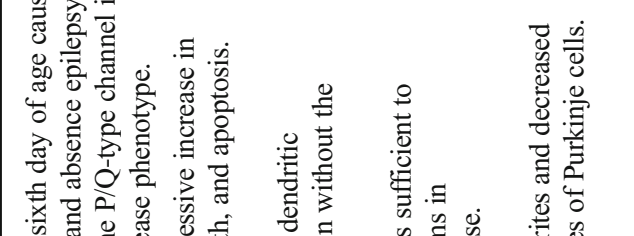

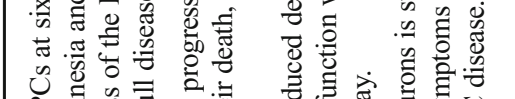

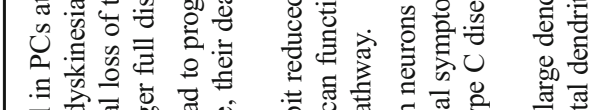

.

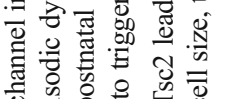

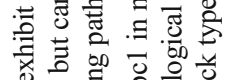

高

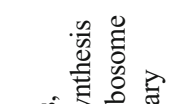

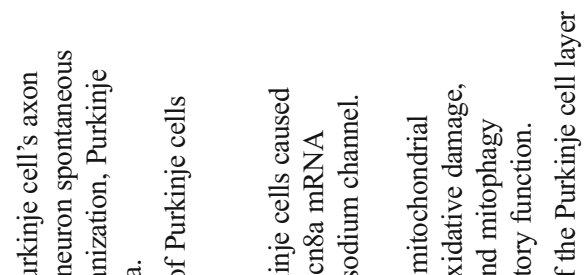

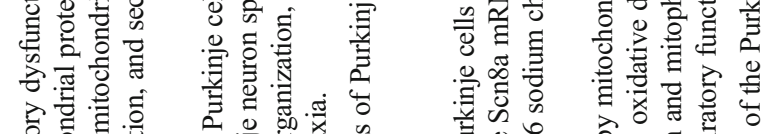

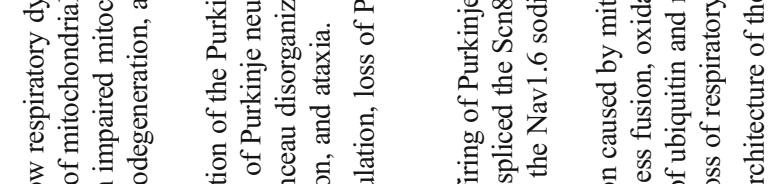

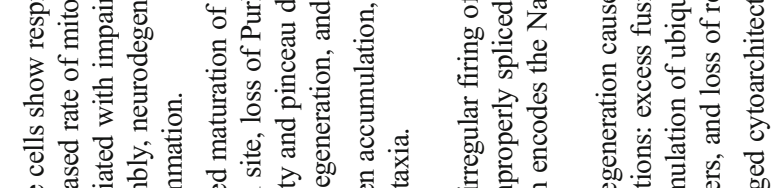

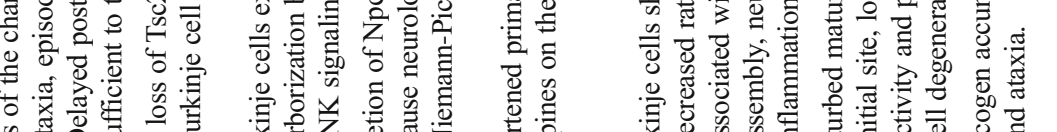

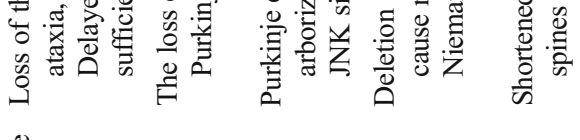

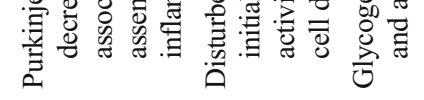

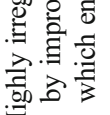

矛

造言 क

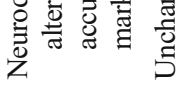

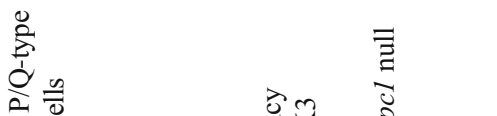

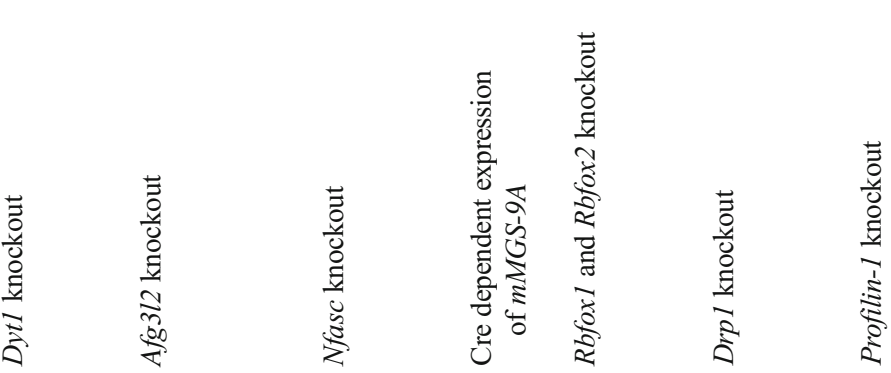

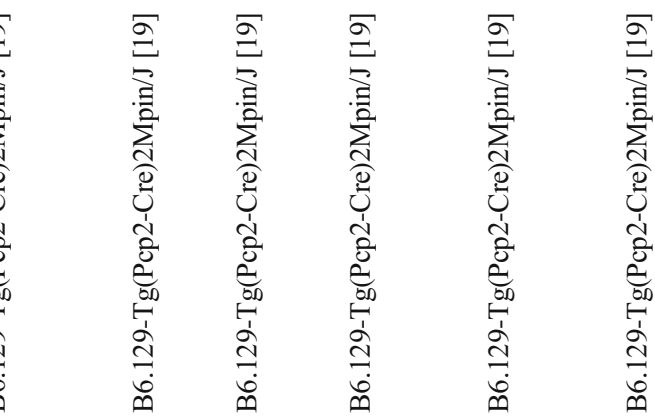

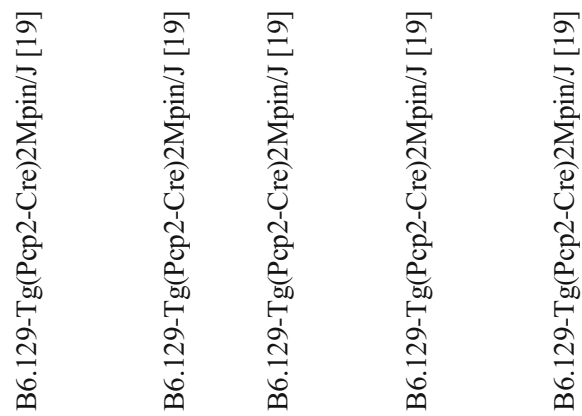

感

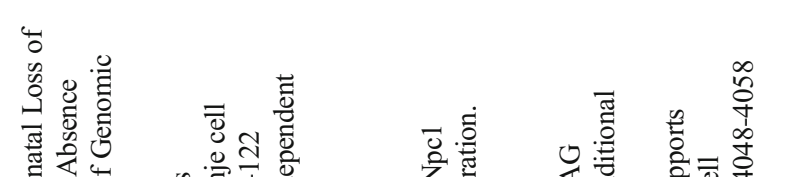

营

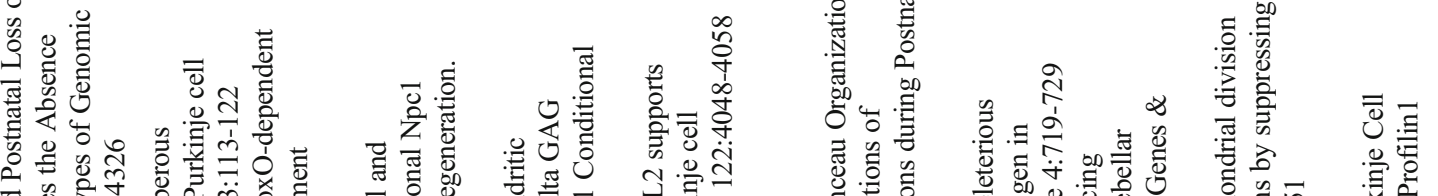

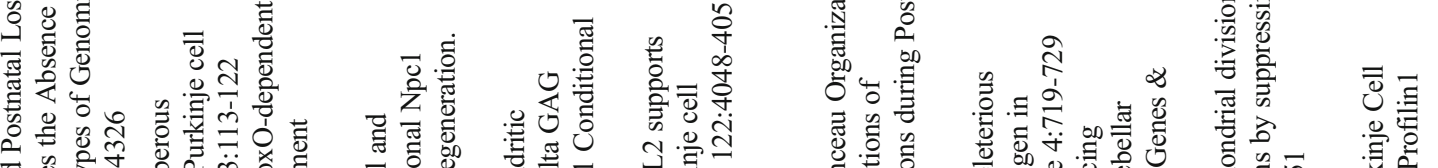

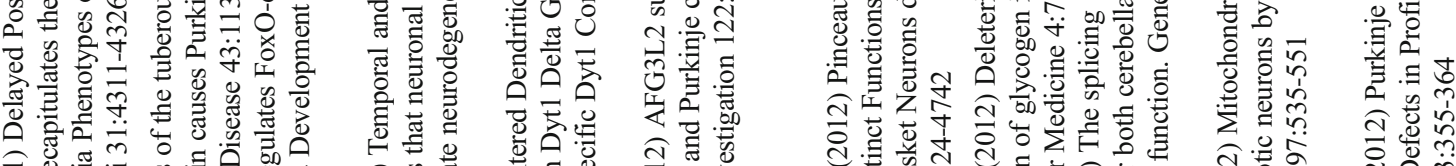

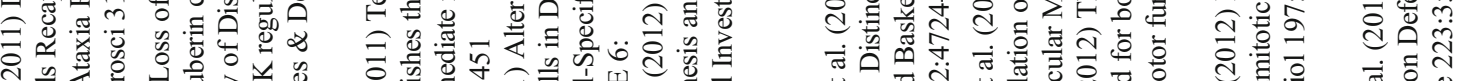

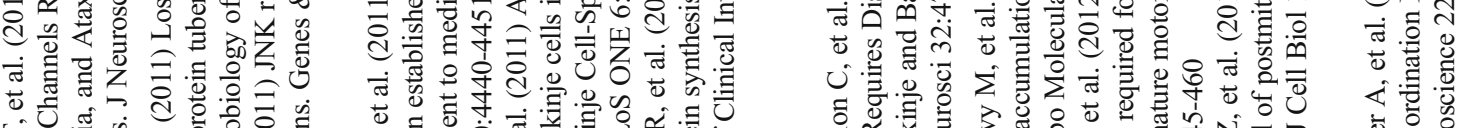

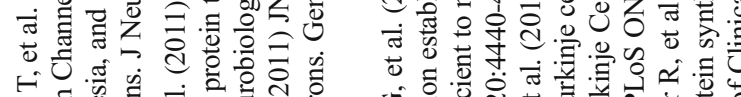

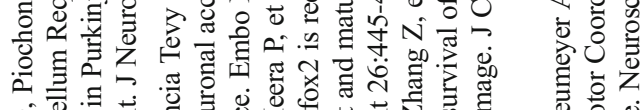

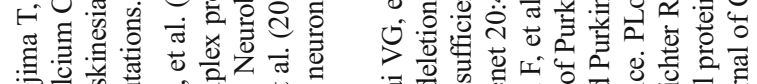

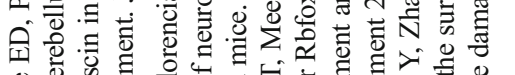

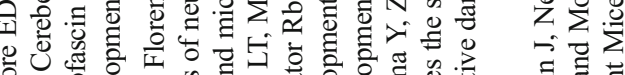

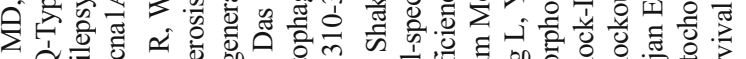

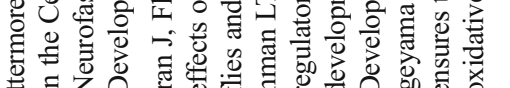

音言

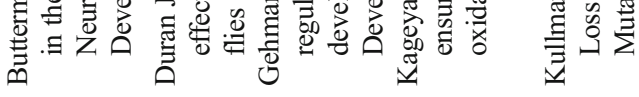




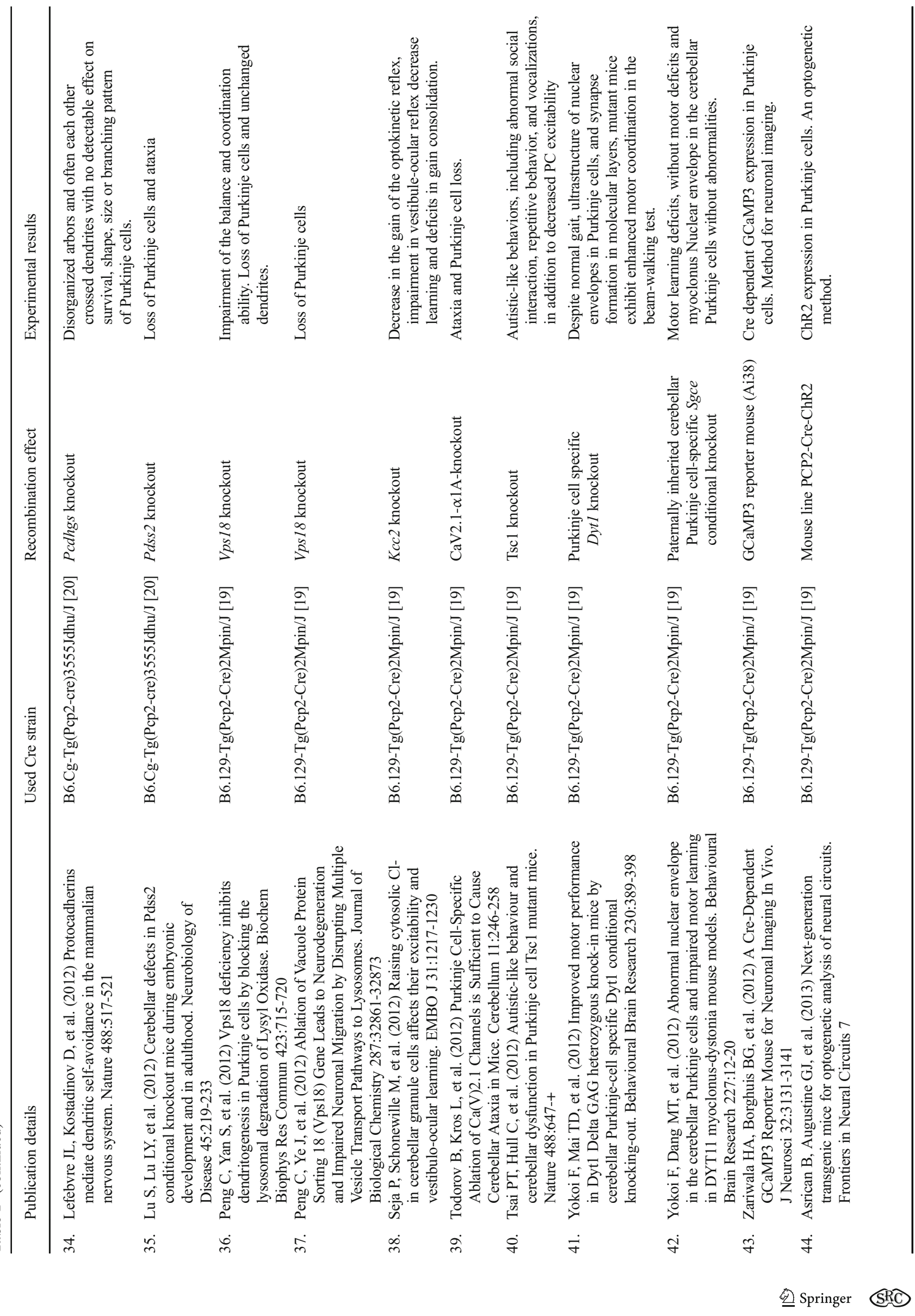




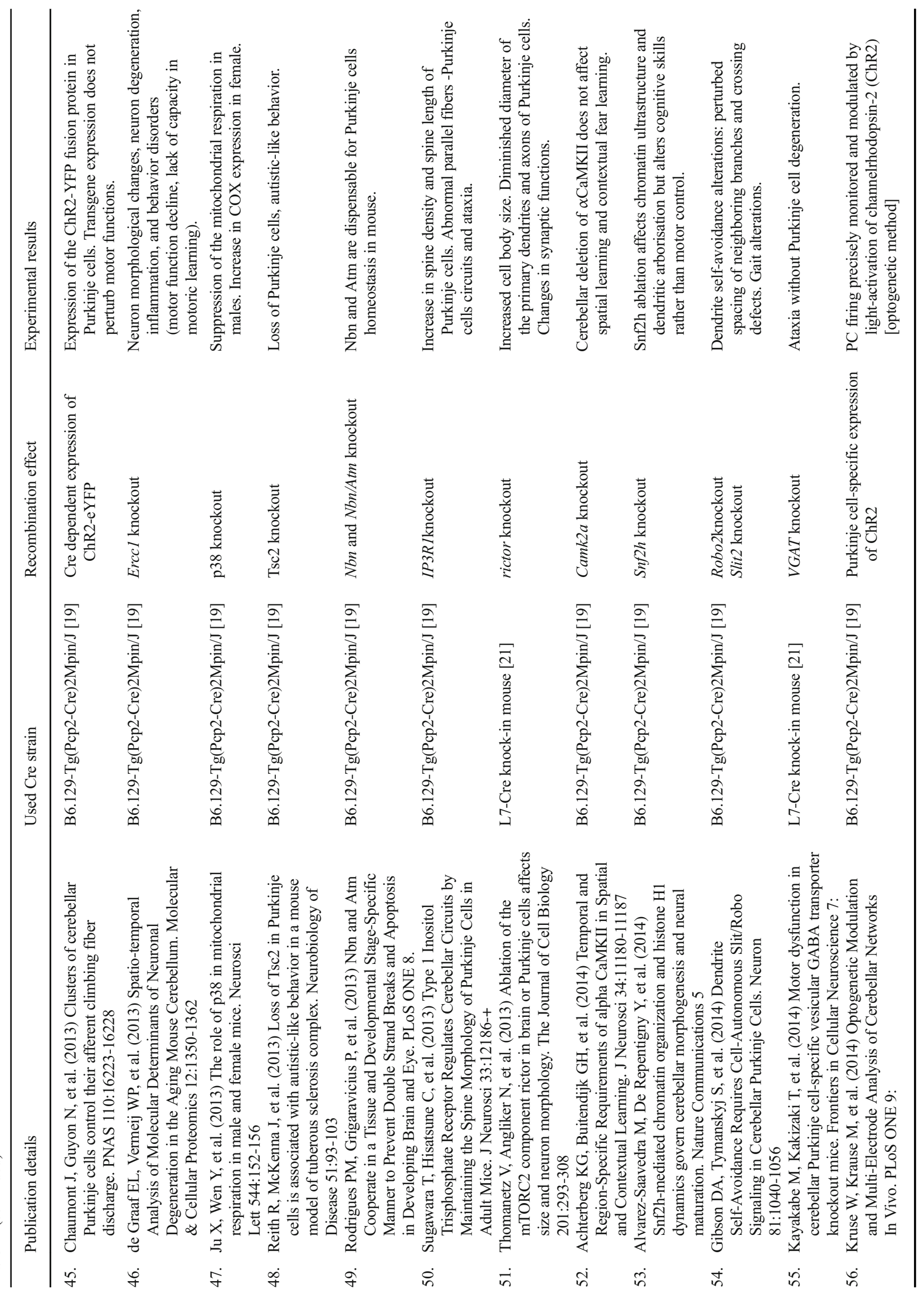




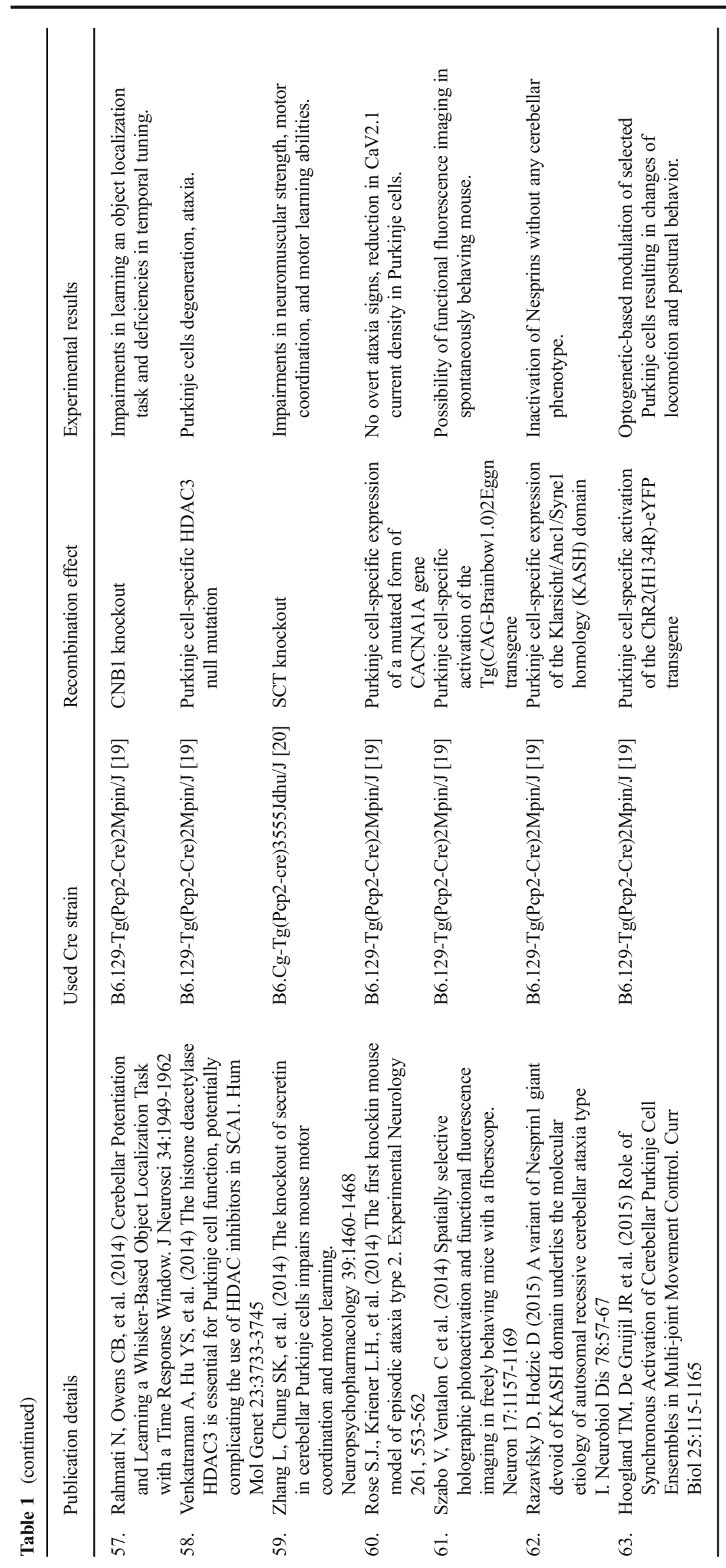


Table 2 Summary of studies utilizing the pcp2 regulatory elements for Purkinje cell specific expression of heterologous genes

$\begin{array}{lll}\text { Publication details } & \text { Experimental approach } & \text { Mutation effect }\end{array}$

1. Zhang X, Baader SL, et al. (2001) High level Purkinje cell specific expression of green fluorescent protein in transgenic mice. Histochem Cell Biol 115:455-64

2. Zu T, Duvick LA, et al. (2004) Recovery from Polyglutamine-Induced Neurodegeneration in Conditional SCA1 Transgenic Mice. J Neurosci 24:8853-8861

3. Wang T, Parris J, et al. (2006) The carboxypeptidase-like substrate-binding site in Nna1 is essential for the rescue of the Purkinje cell degeneration (pcd) phenotype. Mol Cell Neurosci 33:200-213

4. Echigo R, Nakao K, et al. (2009) Generation of L7-tTA knock-in mice. Kobe J Med Sci 54:E272-E278

5. Chang YC, Lin CY, et al. (2011) Neuroprotective effects of granulocyte-colony stimulating factor in a novel transgenic mouse model of SCA17. J Neurochem 118:288-303

6. Wagner W, McCroskery S, et al. (2011) An efficient method for the long-term and specific expression of exogenous cDNAs in cultured Purkinje neurons. J Neurosci Meth 200:95-105

7. Fujita-Jimbo E, Momoi T (2014) Specific expression of FOXP2 in cerebellum improves ultrasonic vocalization in heterozygous but not in homozygous Foxp2 (R552H) knock-in pups. Neurosci Lett 566:162-166
Purkinje-cell specific of GFP

Purkinje-cell specific tetracyclin transactivator expression

Purkinje-cell specific expression of Nna1, a protein with metallocarboxypeptidase domain

Purkinje-cell specific tetracyclin transactivator expression via a knock-in approach

Purkinje-cell specific expression of mutated form of the TATA-binding protein $(h T B P)$ gene

Generation of plasmid transfection system suitable for cell specific expression of various cDNAs in cultured Purkinje cells

Purkinje-cell specific expression of humanFOXP2-myc in mouse cerebellum
Homogenous and stable expression of GFP in cerebellar Purkinje cells.

Purkinje-cell specific inactivation of the ataxin transgene. Partial reversal of ataxia type 1 manifestations.

Partial rescue of ataxia and Purkinje cells degeneration in the $p c d$ strain mice.

Stable and cell specific expression of tTA under the pcp 2 regulatory elements

Generation of an animal model of spinocerebellar ataxia type 17 (SCA17).

Stable and long-term expression of series of fluorescent proteins in Purkinje cells.

Partial rescue of proper ultrasonic vocalizations in FOXP mutant mouse, animal model of language disorders. new approach had an advantage over previous methods - it allows to verify a single cell type specific perturbation instead of rather global effects of a particular neurotransmitter or signaling system malfunction. The study brought a strong evidence that synapse elimination in the CNS needs appropriate electrical activity in the postsynaptic cells [24].

One of the most sophisticated cre/loxP-based methods has been developed and described by Wall et al. In 2010, they published a work about the new tool for retrograde tracing of presynaptic cells. They used two viruses - one the avian sarcoma leucosis virus glycoprotein EnvA-pseudotyped rabbies virus that was capable to infect only cells expressing an avian receptor protein TVA. The second one was the credependent helper virus that contained genes of the abovementioned TVA and the rabies glycoprotein B19G. This allowed the first one virus to spread retrogradely. Moreover, the EnvA-pseudotyped rabbies virus had no B19G gene so was unable to spread in the absence of another source of that glycoprotein. Combination of these viruses with the concomitant cell specific cre expression gave an ability to identify the direct local and long-distance connections to Creexpressing neurons in vivo [25].

Another group of studies focused on PCs employed an optogenetic approach. First of the papers we would like to focus on is from 2011. Gutierrez et al. created an optogenetic mouse model for the cell specific expression of vertebrate rhodopsin ( $\mathrm{vRh}$ ) to investigate the functional impact of $\mathrm{Gi} / \mathrm{o}$ protein mediated modulation on the cerebellar function via the spike modulation in PCs. First, they created mice with a cell-specific expression of $v R h-$ GFP. Secondly, investigators showed that light activation of $v R h$ selectively expressed in PCs, similarly to GABAbR activation by baclofen in PCs, reduces the firing frequency of PCs in vivo. At the end, they conducted series of motor tests confirming that Gi/o-mediated modulation of PC firing alters motor coordination in behaving mice [26].

Comprehensive study of Asrican et al. describes new mouse lines useful for investigation of neural circuits. Researchers compared three strategies for expressing channelrhodopsin-2 (ChR2) in PCs. Pcp-2 promoter was used to target the expression of ChR2 with a H134 mutation and the method was the most selective to Purkinje neurons. The other two lines utilized the parvalbumin promoter and targeted ChR2 expression additionally to other neurons of the cerebellar cortex. Histological analysis revealed significant expression of targeted protein in the cerebellum of all three lines. In contrast to pcp-2based line where ChR2 expression was present only in Purkinje neurons, other two lines displayed expression 
of ChR2 also in molecular layer interneurons. The study demonstrated the convergence of a variable number of Purkinje neurons input onto the deep cerebellar nuclei neurons. Authors emphasized that pcp2-based line was ideally suited for PC circuits mapping by means of the optogenetic method [27].

Other application of Purkinje cell specific ChR2 expression was showed by Kruse et al. in 2014. To analyze neuronal networks Kruse with colleagues employed similar method to precisely monitor and modulate PCs firing but their method was improved by a more targeted application of light. Researchers found that PCs switched on and off in a milliseconds time resolution while being light activated. Same effect on PCs was brought by photo stimulation of molecular layer interneurons, whereas granule cells activation only slowly modulated its firing. These results indicate on the functional modulation of PCs firing rate by accompanying cells [28].

Interesting research opportunities brought also the work of Szabo et al. Their method allowed to control and monitor dynamics of microcircuits in freely behaving mice with almost cellular level resolution [29].

Last one of the most interesting optogenetic experiments in this review comes from Hoogland et al. from May 2015. In this study, mice with mutated P/Q-type calcium channels were subjected to the motor coordination test on a disk treadmill to study motor behavior and then to find correlations between the activity of PC ensembles and motor performance parameters. Optogenetics was applied to evoke simple spike activity simultaneously in multiple Purkinje neurons expressing ChR2(H134R)-eYFP driven by pcp2Cre. Combination of these two methods enabled to characterize walking patterns, and preferred sequences of limb placement after light-induced simple spike activity of PCs groups at rest. During locomotion various gait-inhibition patterns caused by PCs activation could be revealed. Study showed that optogenetically evoked simple spike activity in PC groups can influence the sequence and timing of limb and body movements at rest and during locomotion; output of cerebellar zones in contribution with other downstream regions is involved into coordination of multijoint and multi-limb-mediated movements [30].

Since the publication of the first two papers describing pcp2, there has been a substantial increase in the understanding of cerebellar physiology [2, 3]. It became easier to study cerebellar function by selectively manipulating its sole output-Purkinje cells. The big step forward however was the possibility to switch off genes with putative importance PC physiology and possibility to manipulate activity of their function without affecting neighboring neuronal elements. Purkinje cell specific gene manipulation makes it possible to analyze even single Purkinje cells with the use one of the very modern techniques - optogenetics.
Acknowledgments The authors are grateful to Adam Swiercz for careful reading of the manuscript

\section{Compliance with Ethical Standards}

Conflict of Interest The authors declare that they have no conflict of interest.

Open Access This article is distributed under the terms of the Creative Commons Attribution 4.0 International License (http:// creativecommons.org/licenses/by/4.0/), which permits unrestricted use, distribution, and reproduction in any medium, provided you give appropriate credit to the original author(s) and the source, provide a link to the Creative Commons license, and indicate if changes were made.

\section{References}

1. Barski JJ, Lauth M, Meyer M. Genetic targeting of cerebellar Purkinje cells: history, current status and novel strategies. Cerebellum (London, England). 2002;1(2):111-8.

2. Oberdick J, Levinthal F, Levinthal C. A Purkinje cell differentiation marker shows a partial DNA sequence homology to the cellular sis/ PDGF2 gene. Neuron. 1988;1(5):367-76.

3. Nordquist DT, Kozak CA, Orr HT. cDNA cloning and characterization of three genes uniquely expressed in cerebellum by Purkinje neurons. J Neurosci : Off J Soc Neurosci. 1988;8(12):4780-9.

4. Fletcher C, Norman DJ, Germond E, Heintz N. A multilocus linkage map of mouse chromosome 8. Genomics. 1991;9(4):737-41.

5. Ceci JD. Mouse chromosome 8. Mammalian genome : Off J Int Mamm Genome Soc. 1994;5 Spec No:S124-38.

6. Oberdick J, Schilling K, Smeyne RJ, Corbin JG, Bocchiaro C, Morgan JI. Control of segment-like patterns of gene expression in the mouse cerebellum. Neuron. 1993;10(6):1007-18.

7. Vandaele S, Nordquist DT, Feddersen RM, Tretjakoff I, Peterson AC, Orr HT. Purkinje cell protein-2 regulatory regions and transgene expression in cerebellar compartments. Genes Dev. 1991;5(7): $1136-48$.

8. Luo Y, Denker BM. Interaction of heterotrimeric G protein Galphao with Purkinje cell protein-2. Evidence for a novel nucleotide exchange factor. J Biol Chem. 1999;274(16):10685-8.

9. Natochin M, Gasimov KG, Artemyev NO. Inhibition of GDP/GTP exchange on $\mathrm{G}$ alpha subunits by proteins containing G-protein regulatory motifs. Biochemistry. 2001;40(17):5322-8.

10. Barski JJ, Denker BM, Guan J, Lauth M, Spreafico F, Fertala A, et al. Developmental upregulation of an alternative form of pcp2 with reduced GDI activity. Cerebellum (London, England). 2014;13(2): 207-14.

11. Xu Y, Sulaiman P, Feddersen RM, Liu J, Smith RG, Vardi N. Retinal ON bipolar cells express a new PCP2 splice variant that accelerates the light response. J Neurosci : Off J Soc Neurosci. 2008;28(36):8873-84.

12. Zhang X, Zhang H, Oberdick J. Conservation of the developmentally regulated dendritic localization of a Purkinje cell-specific mRNA that encodes a G-protein modulator: comparison of rodent and human Pcp2(L7) gene structure and expression. Brain Res Mol Brain Res. 2002;105(1-2):1-10.

13. Oberdick J, Smeyne RJ, Mann JR, Zackson S, Morgan JI. A promoter that drives transgene expression in cerebellar Purkinje and retinal bipolar neurons. Science (New York, NY). 1990;248(4952): 223-6. 
14. Berrebi AS, Oberdick J, Sangameswaran L, Christakos S, Morgan JI, Mugnaini E. Cerebellar Purkinje cell markers are expressed in retinal bipolar neurons. J Comp Neurol. 1991;308(4):630-49.

15. Sternberg N, Hamilton D. Bacteriophage P1 site-specific recombination. I. Recombination between loxP sites. J Mol Biol. 1981;150(4):467-86.

16. Chen Y, Rice PA. New insight into site-specific recombination from Flp recombinase-DNA structures. Annu Rev Biophys Biomol Struct. 2003;32:135-59.

17. Smeyne RJ, Chu T, Lewin A, Bian F, Sanlioglu S, Kunsch C, et al. Local control of granule cell generation by cerebellar Purkinje cells. Mol Cell Neurosci. 1995;6(3):230-51.

18. Barski JJ, Dethleffsen K, Meyer M. Cre recombinase expression in cerebellar Purkinje cells. Genesis (New York, NY : 2000). 2000;28(3-4):93-8.

19. Zhang XM, Ng AH, Tanner JA, Wu WT, Copeland NG, Jenkins NA, et al. Highly restricted expression of Cre recombinase in cerebellar Purkinje cells. Genesis (New York, NY : 2000). 2004;40(1):45-51.

20. Saito H, Tsumura H, Otake S, Nishida A, Furukawa T, Suzuki N. L7/Pcp-2-specific expression of Cre recombinase using knock-in approach. Biochem Biophys Res Commun. 2005;331(4):1216-21.

21. Barski JJ, Hartmann J, Rose CR, Hoebeek F, Morl K, Noll-Hussong $\mathrm{M}$, et al. Calbindin in cerebellar Purkinje cells is a critical determinant of the precision of motor coordination. J Neurosci : Off J Soc Neurosci. 2003;23(8):3469-77.

22. Barski JJ, Morl K, Meyer M. Conditional inactivation of the calbindin D-28k (Calb1) gene by Cre/loxP-mediated recombination. Genesis (New York, NY : 2000). 2002;32(2):165-8.

23. Feil R, Hartmann J, Luo C, Wolfsgruber W, Schilling K, Feil S, et al. Impairment of LTD and cerebellar learning by Purkinje cell- specific ablation of cGMP-dependent protein kinase I. J Cell Biol. 2003;163(2):295-302.

24. Lorenzetto E, Caselli L, Feng G, Yuan W, Nerbonne JM, Sanes JR, et al. Genetic perturbation of postsynaptic activity regulates synapse elimination in developing cerebellum. Proc Natl Acad Sci U S A. 2009;106(38):16475-80.

25. Wall NR, Wickersham IR, Cetin A, De La Parra M, Callaway EM. Monosynaptic circuit tracing in vivo through Cre-dependent targeting and complementation of modified rabies virus. Proc Natl Acad Sci U S A. 2010;107(50): 21848-53.

26. Gutierrez DV, Mark MD, Masseck O, Maejima T, Kuckelsberg D, Hyde RA, et al. Optogenetic control of motor coordination by Gi/o protein-coupled vertebrate rhodopsin in cerebellar Purkinje cells. J Biol Chem. 2011;286(29):25848-58.

27. Asrican B, Augustine GJ, Berglund K, Chen S, Chow N, Deisseroth $\mathrm{K}$, et al. Next-generation transgenic mice for optogenetic analysis of neural circuits. Front Neural Circuits. 2013;7:160.

28. Kruse W, Krause M, Aarse J, Mark MD, Manahan-Vaughan D, Herlitze S. Optogenetic modulation and multi-electrode analysis of cerebellar networks in vivo. PLoS One. 2014;9(8), e105589.

29. Szabo V, Ventalon C, De Sars V, Bradley J, Emiliani V. Spatially selective holographic photoactivation and functional fluorescence imaging in freely behaving mice with a fiberscope. Neuron. 2014;84(6):1157-69.

30. Hoogland TM, De Gruijl JR, Witter L, Canto CB, De Zeeuw CI. Role of synchronous activation of cerebellar Purkinje cell ensembles in multi-joint movement control. Curr Biol : CB. 2015;25(9): 1157-65. 